\title{
Dynamic interplay between breast cancer cells and normal endothelium mediates the expression of matrix macromolecules, proteasome activity and functional properties of endothelial cells $s^{\text {ts }}$
}

\author{
Ch. Gialeli ${ }^{\text {a,b }}$, M. Viola ${ }^{c}$, D. Barbouri ${ }^{\text {a,b }}$, D. Kletsas ${ }^{\text {d }}$, A. Passi ${ }^{\text {c }}$, N.K. Karamanos ${ }^{\text {a,b,* }}$ \\ a Biochemistry, Biochemical Analysis E Matrix Pathobiology Res. Group, Laboratory of Biochemistry, Department of Chemistry, University of Patras, 26110 Patras, Greece \\ ${ }^{\mathrm{b}}$ Foundation for Research and Technology, Institute of Chemical Engineering Sciences (FORTH/ICE-HT), 26500 Patras, Greece \\ c Department of Surgery and Morphological Sciences, University of Insubria, Varese, Italy \\ d Laboratory of Cell Proliferation and Ageing, Institute of Biology, National Center of Scientific Research “Demokritos", Athens, Greece
}

\section{A R T I C L E I N F O}

\section{Article history:}

Received 1 December 2013

Received in revised form 6 February 2014

Accepted 14 February 2014

Available online 26 February 2014

\section{Keywords:}

Breast cancer cell

Endothelium

Extracellular matrix

Hyaluronan

Proteosome

Cell functional properties

\begin{abstract}
A B S T R A C T
Background: Breast cancer-endothelium interactions provide regulatory signals facilitating tumor progression. The endothelial cells have so far been mainly viewed in the context of tumor perfusion and relatively little is known regarding the effects of such paracrine interactions on the expression of extracellular matrix (ECM), proteasome activity and properties of endothelial cells.

Methods: To address the effects of breast cancer cell (BCC) lines MDA-MB-231 and MCF-7 on the endothelial cells, two cell culture models were utilized; one involves endothelial cell culture in the presence of BCCs-derived conditioned media (CM) and the other co-culture of both cell populations in a Transwell system. Real-time PCR was utilized to evaluate gene expression, an immunofluorescence assay for proteasome activity, and functional assays (migration, adhesion and invasion) and immunofluorescence microscopy for cell integrity and properties.

Results: BCC-CM decreases the cell migration of HUVEC. Adhesion and invasion of BCCs are favored by HUVEC and HUVEC-CM. HA levels and the expression of CD44 and HA synthase- 2 by HUVEC are substantially upregulated in both cell culture approaches. Adhesion molecules, ICAM-1 and VCAM-1, are also highly upregulated, whereas MT1-MMP and MMP-2 expressions are significantly downregulated in both culture systems. Notably, the expression and activity of the proteasome $\beta 5$ subunit are increased, especially by the action of MDA-MB-231-CM on HUVEC.

Conclusions and general significance: BCCs significantly alter the expression of matrix macromolecules, proteasome activity and functional properties of endothelial cells. Deep understanding of such paracrine interactions will help to design novel drugs targeting breast cancer at the ECM level. This article is part of a Special Issue entitled Matrix-mediated cell behaviour and properties.
\end{abstract}

(c) 2014 Elsevier B.V. All rights reserved.

\section{Introduction}

Cancer is a remarkably diverse disease, characterized by distinctive and complementary hallmark capabilities, involving sustained

Abbreviations: ECM, extracellular matrix; BCC, breast cancer cell; CM, conditioned media; TEM, trans-endothelial migration; GAG, glycosaminoglycan; HS, heparan sulfate; CS, chondroitin sulfate; HA, hyaluronan; UPS, ubiquitin proteasome system; FBS, fetal bovine serum; HUVEC, human umbilical vein endothelial cells; BCC-CM, breast cancer cells CM; CAMs, cell adhesion molecules; ICAM-1, intercellular cell adhesion molecule-1; VCAM-1, vascular endothelial cell adhesion molecule-1; MMPs, Matrix metalloproteinases; MT1-MMP, membrane-type-1-MMP

This article is part of a Special Issue entitled Matrix-mediated cell behaviour and properties.

* Corresponding author at: Laboratory of Biochemistry, Department of Chemistry, University of Patras, 26110 Patras, Greece. Fax: +30 2610997153.

E-mail address: n.k.karamanos@upatras.gr (N.K. Karamanos). proliferation or evasion of cell death and immune system destruction, activated invasion and metastasis, induced angiogenesis as well as reprogrammed energy metabolism that coordinate tumor progression $[1,2]$. The importance of the tumor microenvironment is becoming increasingly appreciated given the fact that tumors are not only self-sufficient moieties but also recruit normal cells of the underlying stroma in favor of tumor progression [3-6]. Metastasis represents a key event of this process that depends on the ability of the cancer cells to grow, degrade the host stroma, migrate into a complex network of macromolecules; extracellular matrix (ECM), adhere, possibly transmigrate through the endothelium into and out of the blood stream and lastly invade the tissue where the metastasis will establish.

In the present study, we focused on a crucial player of this reciprocal relationship between cancer cells and tumor microenvironment, the endothelial cells. The endothelium is highly specialized and its origin varies considerably from tissue to tissue and organ to organ $[4,7]$. 
During extra- and intra-vasation, cancer cells undergo critical interactions and establish active contacts with the endothelium that entail remarkable cytoskeletal changes prerequisite for trans-endothelial migration (TEM) into the underlying matrix and stroma [8,9]. Several cancer cell surface molecules have been documented to counteract with molecules on the endothelial cell surface. Among them selectins, integrins, CD44 and the adhesion molecules ICAM, VCAM contribute in that way to the "docking-locking" hypothesis [9].

It is well established that cellular behavior is highly regulated by ECM, and as a consequence cancer progression is dependent on its unique properties, involving alterations in ECM components' structure and/or expression as well as the activity modifications that take place during this process $[10,11]$. Endothelial glycocalyx represents a negatively charged organized network of ECM macromolecules that lines a healthy vascular endothelium. This scaffold consists of a variety of transmembrane- and membrane-attached molecule proteoglycans (syndecan-1, -2, -4 and glypican-1), as well as cell adhesion molecules (integrins, selectins), inflammatory regulators and adsorbed components (coagulation system) $[12,13]$. In addition secreted proteoglycans (mimecan, perlecan, and biglycan) reside in the glycocalyx interface or diffuse into the blood stream $[14,15]$. The most prominent glycosaminoglycan (GAG) incriminated on the surface of endothelial cells is heparan sulfate (HS) accounting for 50\%-90\% of the total GAG pool, and the rest being composed of chondroitin sulfate (CS) and hyaluronan (HA), with levels depending on cell types [16].

Regardless of its source, the endothelium exerts critical functions in several aspects of cancer biology including tumor progression, angiogenesis, and metastasis. It is documented to regulate angiogenesis in order to provide nutrients, oxygen, and other solutes through the bloodstream to the tumor, supply of paracrine factors recruiting other stromal players like immune cells to the tumor site and modulation of cancer cell dissemination $[17,18]$. An additional level in the complexity of the interplay between cancer cells and endothelial cells arises from the dynamic interaction of glycocalyx with the local microenvironment as endothelial cells have high rates of continuous metabolic turnover that allow adaptation to changes [19]. Compelling evidence also suggests that the glycocalyx on endothelial cells functions as a matrix barrier. It is well established that tumor cell adhesion to the microvessel wall degrades the endothelial surface glycocalyx layer [20]. Taken all together, cancer cell extravasation is induced by the disruption of this layer by pro-inflammatory cytokines and degrading enzymes produced by cancer cells, thereby influencing vascular endothelial barrier integrity [21-25]. On the other hand, the endothelial glycocalyx composition is able to act itself as a positive or negative modulator of cell adhesion to endothelium. For example, if the size of constituent parts of the endothelial surface layer such as HS proteoglycans and hyaluronan is greater than the size of adhesion molecules, the adherence of cells is prevented [26]. On the other hand, endothelial derived hyaluronan serves as ligand for its adjacent receptor CD44 expressed in cancer cells [27]. Furthermore, endothelial glycocalyx entraps growth factors via the glycosaminoglycan chains of proteoglycans, increasing in that way the endothelial permeability [23]. In addition, it reported that through all of these steps of active interaction between cancer cells and the endothelium, both parties undergo critical cytoskeletal changes to facilitate such interplay [28,29].

Proteasome is a major cellular protease complex that regulates nonlysosomal degradation, thus in turn controlling the concentration and turnover of ECM [30]. Several proteasome inhibitors are proposed as novel anti-cancer agents, exerting anti-tumor activity in vivo. Apart from its role in cancer cell apoptosis/growth, ubiquitin proteasome system (UPS) has been indicated in several cases directly or indirectly to the dys-function of the endothelial front.

The reciprocal interactions between the endothelium and cancer cells are a complex scenario that is not fully characterized yet. In the present study, we therefore focus on the evaluation of the effects of breast cancer cells on the endothelium microtubules and functional properties, expression of matrix and cell surface effectors (endothelial glycocalyx composition) and proteasome activity.

\section{Materials and methods}

\subsection{Chemicals and reagents}

FBS (fetal bovine serum), DMEM, sodium pyruvate, L-glutamine, penicillin, streptomycin, amphotericin $B$ and gentamycin were all obtained from Biochrom (Berlin, Germany).

\subsection{Cell cultures}

Human umbilical vein endothelial cells (HUVECs) were purchased from Lonza (Walkersville, USA) and were grown for 2-6 passages in EGM2 culture medium (Lonza) supplemented with $2 \%$ fetal bovine serum. The cultures were maintained in an atmosphere of humidified $95 \%$ air, $5 \% \mathrm{CO}_{2}$ at $37{ }^{\circ} \mathrm{C}$.

Breast cancer cells of human breast adenocarcinoma, MDA-MB-231 (ATCC $®$ HTB-26) and MCF-7 (ATCC $®$ HTB-22) were obtained from the American Tissue Culture Collection. Breast cancer cells were cultured in DMEM supplemented with 10\% (v/v) FBS, $1.0 \mathrm{mM}$ sodium pyruvate, and a cocktail of antimicrobial agents $(100 \mathrm{IU} / \mathrm{mL}$ penicillin, $100 \mu \mathrm{g} / \mathrm{mL}$ streptomycin, $10 \mu \mathrm{g} / \mathrm{mL}$ gentamycin sulfate and $2.5 \mu \mathrm{g} / \mathrm{mL}$ amphotericin B). Cells were routinely grown at $37{ }^{\circ} \mathrm{C}$ in a humidified atmosphere of $5 \%(\mathrm{v} / \mathrm{v}) \mathrm{CO}_{2}$. Culture medium was changed every $48-72 \mathrm{~h}$. Cells were harvested by trypsinization with $0.05 \%(\mathrm{w} / \mathrm{v})$ trypsin in PBS containing $0.02 \%(\mathrm{w} / \mathrm{v}) \mathrm{Na}_{2}$ EDTA.

\subsection{Experimental sets}

Two experimental approaches were utilized; one involves endothelial cell culture in the presence of breast cancer cell-derived conditioned media (BCC-CM) and the other co-culture of both cell populations in a Transwell system using $0.4 \mu \mathrm{M}$ microporous membrane (Fig. 1). In some cases the effect on HUVEC CM on breast cancer cells culture was also evaluated. In the CM experimental approach, the role of the produced factors under growing conditions and their effect on the adjacent microenvironment were evaluated. Introducing to our approach the element of cell-cell communication, the co-culture transwell system was utilized where breast cancer cells and HUVEC interact and exchange soluble factors between the microporous membrane.

HUVEC (BCC-CM approach). Six hours before treatments, subconfluent (ca 70\%) HUVECs were cultured in EGM2 with $0.2 \%$ fetal bovine serum. The medium was then changed to EGM2 plus 2\% fetal bovine serum supplemented with equal amount of BCC-CM and incubated for $24 \mathrm{~h}$ (Fig. 1A).

Cancer cells (HUVEC-CM approach). Six hours before treatments, subconfluent breast cancer cells (ca 70\%) were cultured in serum free DMEM. The medium was then changed to DMEM plus $2 \%$ fetal bovine serum supplemented with equal amount of HUVEC-CM and incubated for $24 \mathrm{~h}$ (Fig. 1B).

Conditioned media (BCCs-CM \& HUVEC-CM) were generated from confluent cell monolayers by $24 \mathrm{~h}$ of culture in the appropriate culture medium. Cells and debris were removed by centrifugation ( $5 \mathrm{~min}$, $500 \times g$ ), and media were aliquoted and stored at $-80{ }^{\circ} \mathrm{C}$. In each case the culture media of the adjacent utilized $\mathrm{CM}$ media served as negative control of the experiment.

Transwell approach. HUVEC (lower chamber) and breast cancer cells (upper chamber) are co-cultured in EGM2 plus 2\% and DMEM plus $2 \%$, respectively using a transwell insert with $0.4 \mu \mathrm{M}$ microporous membrane. Control HUVEC were cultured in the presence of culture media of BCCs in the upper chamber. Before the incubation cell monolayers were serum starved like the CM approach (Fig. 1C). 

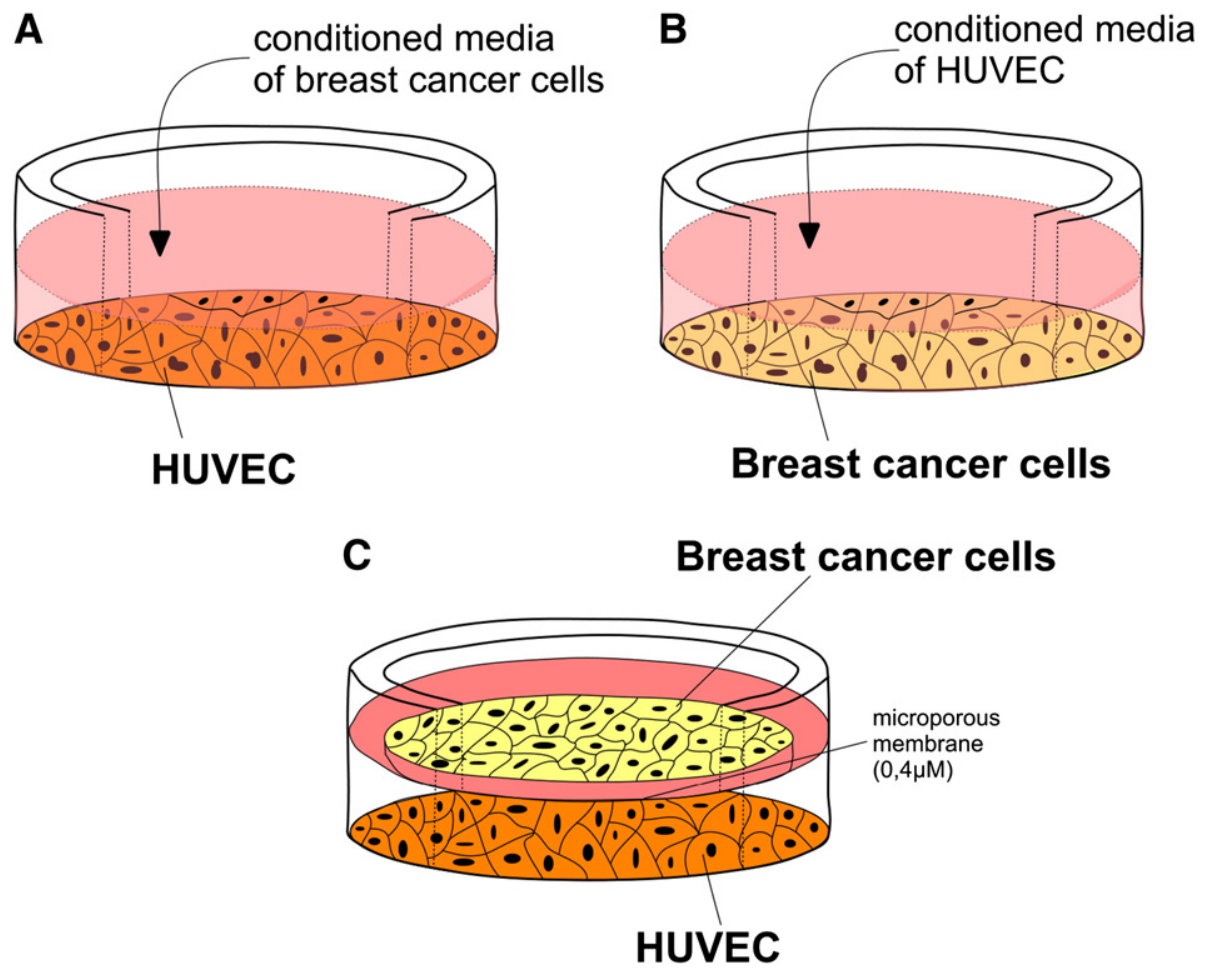

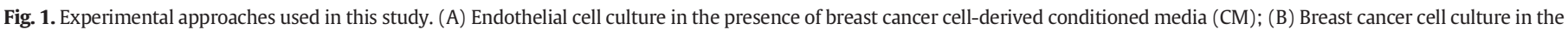
presence of HUVEC-derived conditioned media (CM); (C) Co-culture of both cell populations in a Transwell system using $0.4 \mu \mathrm{M}$ microporous membrane.

\subsection{Functional assays}

\subsubsection{In vitro wound healing assay}

HUVEC confluent cell layers were wounded by scratching with a sterile $10 \mu \mathrm{L}$ pipette tip. Detached cells were removed by washing two times with PBS and fresh culture medium was added in the absence or presence of conditioned media. The wound closure was monitored at $0,6,12,24 \mathrm{~h}$ using a digital camera connected to a microscope. Wound surface area was quantified by image analysis (Image 1.4.3.67 Launcher Symmetry Software).

\subsubsection{Breast cancer cell invasion assay}

The invasive potential of breast cancer cells was evaluated using Transwell inserts [Chemicon (Millipore) QCM ${ }^{\mathrm{TM}}$, ECM550]. Each insert (invasion chamber) bottom possesses an 8 - $\mu$ m pore size polycarbonate membrane, over which a thin layer of ECMatrixTM is dried. Prior to cell invasion assay, the cells were treated with or without HUVEC-CM. Cells ( ca 240,000) per invasion chamber in serum-free culture medium were seeded and allowed to invade for $24 \mathrm{~h}$ at $37{ }^{\circ} \mathrm{C}$ using $10 \%$ FBS culture medium or HUVEC-derived CM as chemo-attractant in the lower chamber. During the incubation a percentage of the cells adhere, invade the layer of ECM and then migrate to the bottom of the membrane. Noninvasive cells are removed with a cotton swab and invasive cells are stained on the lower surface of the membrane with Crystal violet. The membrane is photographed using a digital camera connected to a microscope. Then, stained cells are diluted in 10\% (v/v) acetic acid and the color measured with an ELISA plate reader at $560 \mathrm{~nm}$.

\subsubsection{Breast cancer cell adhesion assay}

Cancer cells were loaded with cell tracker Red CMTPX (Invitrogen, Milan, Italy) (working solution concentration $10 \mu \mathrm{M}$ ) and incubated for 30 min at growing conditions, according to the manufacturer's instructions. Labeled-cancer cells are plated on treated and untreated HUVEC cell monolayer. HUVEC cell monolayer was pre-treated with $1000 \mathrm{U} / \mathrm{mL}\left(1 \mathrm{~h} 37^{\circ} \mathrm{C}\right)$ of hyaluronidase (Seikagaku Corporation, Tokyo, Japan) or EDTA buffer ( $1 \mathrm{mM}$ EDTA pH 7.4, 10 min at $37^{\circ} \mathrm{C}$ ).
After $3 \mathrm{~h}$ incubation period and PBS washing, the numbers of adherent cancer cells on HUVEC cell monolayer were assessed under a fluorescent microscope (Olympus, Segrate, Italy).

\subsection{RNA isolation and real-time PCR}

Total RNA samples were extracted from HUVEC and breast cancer cells with Trizol (Invitrogen, Milan, Italy). For quantitative RT-PCR, RNA samples that were previously digested with Turbo DNase (Ambion, Monza, Italy) were retrotranscribed using the High Capacity cDNAsynthesis kit (Applied Biosystems, Monza, Italy) and amplified on an Abi Prism 7000 instrument (Applied Biosystems, Monza, Italy) using the Taqman Universal PCR Master Mix (Applied Biosystems) following the manufacturer's instructions.

The following human TaqMan gene expression assays were used: CD44 (HS00174139_m1), HAS2 (Hs00193435_m1), ICAM (Hs00164932), VCAM (Hs00174239), MMP-2 (Hs00234422_m1), MT1-MMP (Hs00237119_m1), ß5subunit F: GGC AAT GTC GAA TCT ATG AGC, R: GTT CCC TTC ACT GTC CAC GTA and $\beta$-actin (Hs99999903_m1). Fluorescent signals generated during PCR amplifications were monitored and analyzed with Abi Prism 7000 SDS software (Applied Biosystems). Comparison of the amount of each gene transcript among different samples was made using RNAseP as the reference. In order to determine the efficiency of each Taqman gene expression assay, standard curves were generated by serial dilution of cDNA, and quantitative evaluations of target and housekeeping gene levels were obtained by measuring threshold cycle numbers $(\mathrm{Ct})$. As the differences among efficiencies of each Taqman gene expression assay were $<0.1$, the relative quantification of gene expression was determined by comparing $2^{-\Delta \Delta \mathrm{Ct}}[31]$.

\subsection{Hyaluronan expression solid phase assay}

The hyaluronan expression of HUVEC in the culture medium was determined by Corgenix HA Test kit, a sandwich protein binding solid phase assay (Corgenix, USA). The concentration of the produced HA 
was normalized in respect to the concentration of the un-treated cells. In turn, the media was assayed according to the manufacturers' instructions.

\subsection{Proteasome activity assay}

Chymotrypsin-like activity ( $\beta 5$ ) was measured using SucLLVY-7amido-4-methylcoumarin (AMC). The fluorogenic proteasome substrate was added to the cell lysate at a final concentration of $80 \mu \mathrm{M}$ in $1 \%$ DMSO. ATP-dependent cleavage activity was monitored continuously by detection of free 7-amido-4-methylcoumarin using a fluorescence plate reader at $380 / 460 \mathrm{~nm}$ at $37^{\circ} \mathrm{C}$.

\subsection{Immunofluorescence staining of endothelial microtubules}

HUVECs were seeded on glass coverslips in 6-well plates and grown to confluence prior to treatment. Cells were washed twice with PBS buffer, fixed in $4 \%$ formaldehyde in PBS buffer, washed three times with PBS-Tween buffer, permeabilized with freshly made $0.5 \%$ Triton X-100 in PBS, washed three times with PBS-Tween buffer and blocked with 5\% BSA in PBS-Tween. Endothelial microtubules were visualized ( $\times 60$ magnification) by immunofluorescence staining using a mouse monoclonal antibody against $\alpha$-tubulin (1:100; Sigma) and an Alexa Fluor 594 anti-mouse second antibody (1:2000; Invitrogen), and the coverslips were mounted on microscope slides. Alterations in HUVEC microtubule morphology were assessed by comparison of photographs of control and treated endothelial cells from three individual experiments.

\subsection{Statistical analysis}

In all experiments, the mean values \pm standard deviations (SD) for determinations in triplicate were calculated. Statistically significant differences were evaluated using the ANOVA test. Differences were considered statistically significant at the level of at least $p \leq 0.05$.

\section{Results \& discussion}

Conventional models of carcinogenesis suggest that endothelial cells are closely related with tumor perfusion. This concept has been challenged introducing the endothelium not only as a passive strong barrier against cancer cells [32], but also as a stromal regulator during tumor progression [33]. It is well established via the "seed and soil" notion that cancer cells receive signals via growth factors that produce themselves or provided by the surrounding stroma, promoting a tumorigenic phenotype.
In this study, we evaluated how breast cancer cells themselves signal the stroma and specifically the endothelium for their benefit and vice versa. To start, using a chemokinetic model, we evaluated HUVEC migration by wound healing assay upon treatment with breast cancer cellderived conditioned media (BCC-CM). HUVEC exhibited a significant time-dependent reduced motility (Fig. 2A). This effect was evident even at the short time of $6 \mathrm{~h}$ and especially upon treatment with CM derived by the highly invasive MDA-MB-231 breast cancer cells (30-40\%). It should be noted that wound closure depends on both migration and proliferation of the cells, with the latter one affecting more the migration assay at higher time points. On the other hand, the migration of breast cancer cells was up-regulated (15-30\%) with the use of HUVEC derived-CM in a time-dependent mode (Fig. $3 \mathrm{~A}-\mathrm{C}$ ). The reduced motility of HUVEC observed by treatment with BCC-CM may well be related to the increased adhesive properties that in turn facilitate the formation of "holes" within the endothelial front. This in combination with the increased motility of breast cancer cells mediated by the HUVEC-derived CM may further facilitate breast cancer cell progression.

The coordinated regulation of cell adhesion and cell motility in a three-dimensional (3D) matrix, in other words, cell invasion, is the driving force in malignancies. It is well established that cancer cells in order to establish distant metastasis invade the underlying stroma as a prerequisite. In an attempt to assess a tumor microenvironment mimetic model, cell invasion was evaluated using a transwell chamber coated with ECM matrix and as chemoattractant HUVEC-derived CM. As shown in Fig. 4A, the invasive potential of the highly metastatic MDAMB-231 breast cancer cells through an ECM matrix was induced (ca 50\%) upon pre-activation of cancer cells by HUVEC-CM using as chemo attractant either fetal bovine serum (data not shown) or HUVEC-CM. However, the invasiveness of the weakly metastatic MCF7 cells was not affected (data not shown). Similar results were extracted by another line of studies where the co-culture of endothelial cells and MDA-MB-231 cells on a three-dimensional matrix, establishing direct cell-cell contacts, resulted in increased breast cancer cell invasiveness [28]. The signals transmitted by the coordinated interplay of cancer and endothelial cells create an inflammatory environment and a pool of growth factors that enhances contractile force generation and cytoskeletal remodeling of both parties, and thereby high transmigration and invasion rates of the cancer cells [34-37]. The ability of cancer cells to adhere to the endothelial cells is also of vital importance in their line of crosstalk. In this study, we reported a highly adhesive profile of the breast cancer cells on HUVEC monolayer in comparison to common plastic culture surface area (Fig. 4B). To strengthen this notion, such high adhesion was further enhanced on HUVEC-produced ECM (ca $60 \%$ for MCF-7 and $150 \%$ for the highly metastatic MDA-MB-231 breast cancer cells as compared to control cells) upon pre-treatment with EDTA. On the other hand, treatment with hyaluronidase enzyme

\section{HUVEC migration}

A

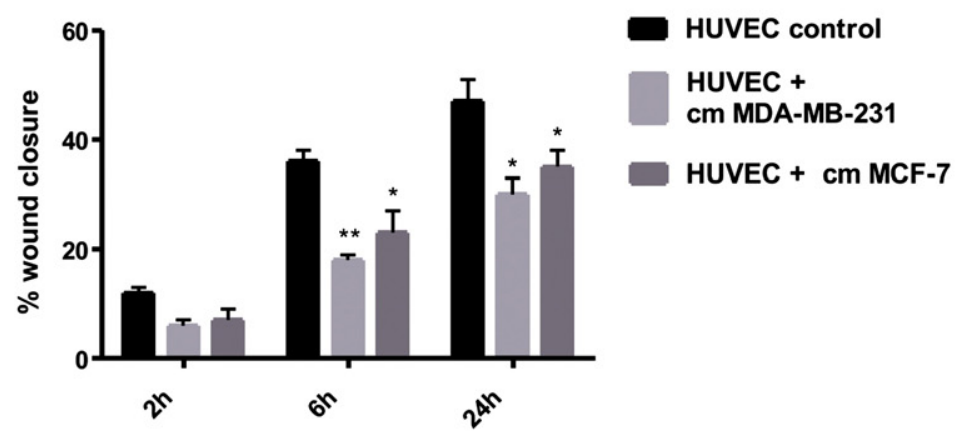

B

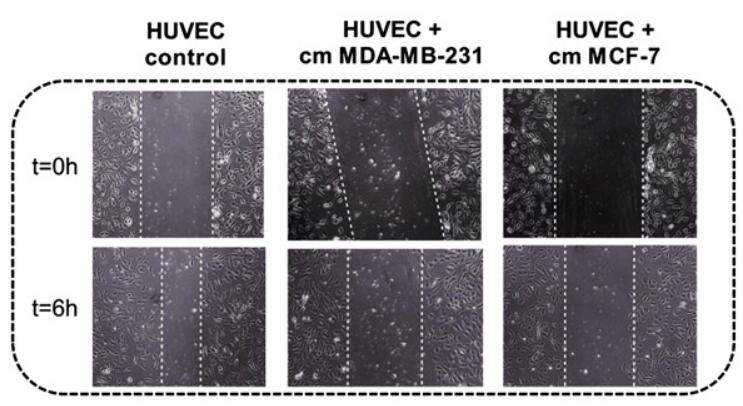

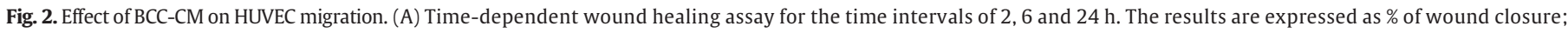

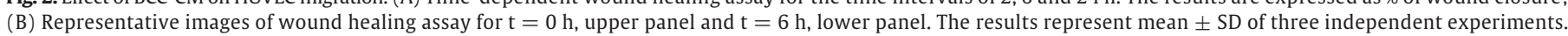
Symbols mark the statistically significant levels as follows: $\left({ }^{*}\right)$ and $\left({ }^{* *}\right)$ indicate $p<0.05$ and $p<0.01$, respectively, as compared to control cells and respective time interval. 

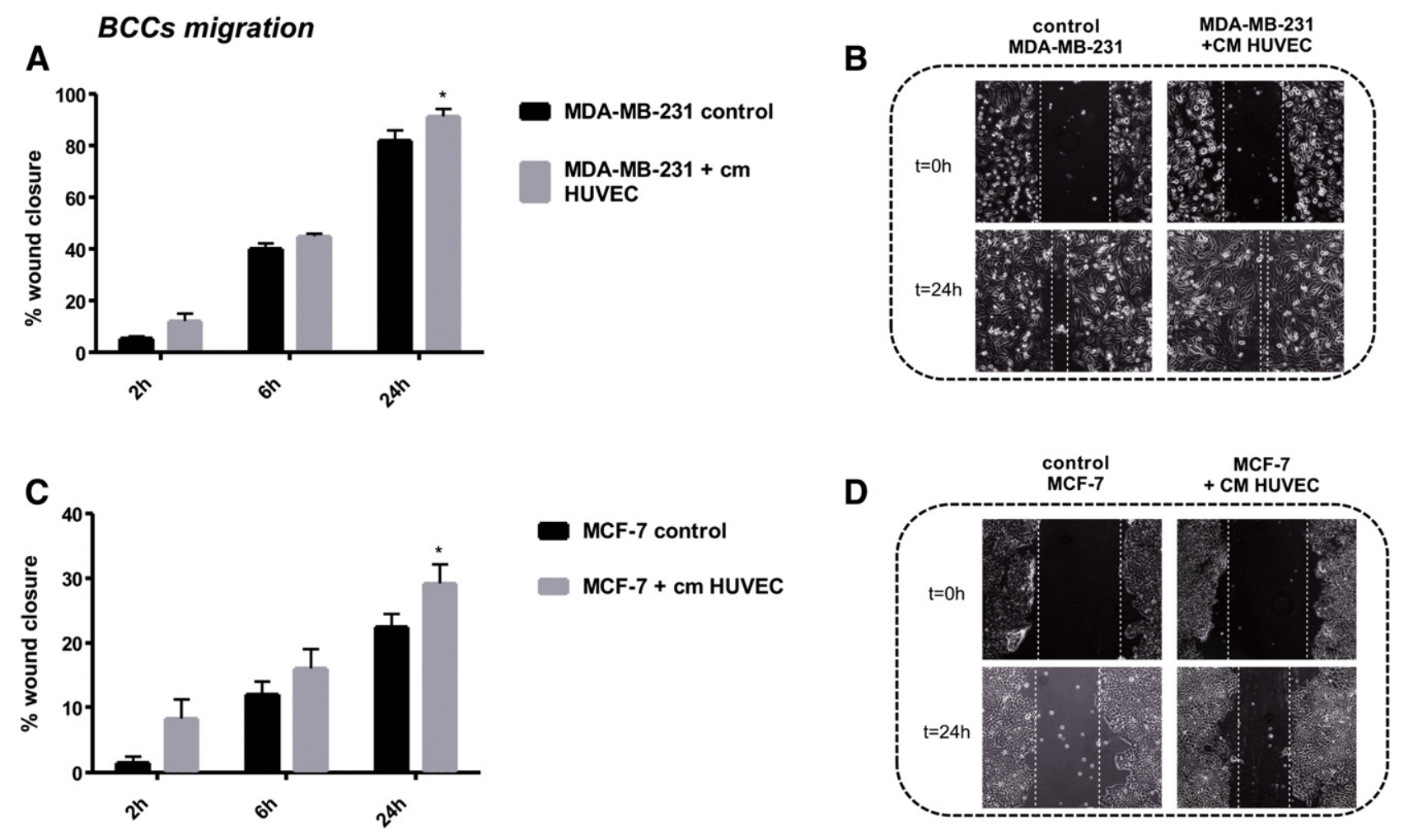

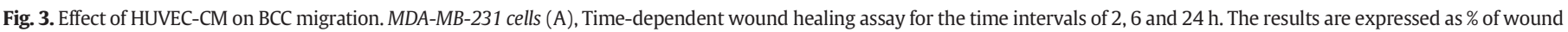

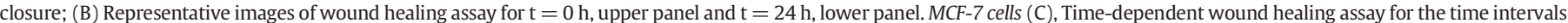

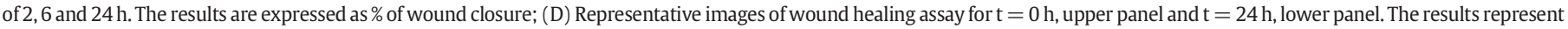
mean \pm SD of three independent experiments. Symbol marks the statistical significant levels as follows: $\left({ }^{*}\right)$ indicates $p<0.05$ as compared to control cells of its time interval.

that degrades HA, leads to the abolishment of the enhanced observed adherence is abolished (Fig. 4C). Collectively, these observations lead us to the conclusion that cancer cells signal the endothelial cells' ECM and vice versa, in such a way favoring the directional migration and adherence of cancer cells.

Several emerging findings introduced cancer cells as transmitters and generators of high contractile forces in order to transmigrate though the endothelium [38]. The principal mediator of these forces is the actomyosin cytoskeleton, as cancer cells create a "leaky" endothelial front and move along the endothelial acto-myosin filaments [39]. Specifically, actin cytoskeleton serves as migration grid for transendothelial migration of cancer cells [40]. In the present study, the morphology of tubulin networks in HUVEC was investigated by immunofluorescence staining using an antibody against $\alpha$-tubulin. Untreated HUVEC possessed low degree formation of tubulin filaments (Fig. 5). Treatment of HUVEC with BCC-CM induced the formation of tubulin filaments as well as banding of tubulin filaments. An overall solid cytoskeletal scaffold is required from endothelial cells in order to hold the endothelial lining against the transmigrating cancer cells. Gross morphological changes were not observed in our experiments, whereas microtubule plasticity/ dynamics were indicated in correlation with altered endothelial cell migration and the "leaky" endothelial barrier for cancer cells.

In another line of study, it was documented that the adhesion of MDA-MB-231 to the vasculature originated in disruption of the endothelial cell barrier via the degradation of the endothelial glycocalyx [20]. Using real-time visualization, it was reported that the endothelium is irreversibly damaged at the site of cancer cell transendothelial migration [41]. Functional HUVEC properties are regulated by their glycocalyx and especially ECM structure and ECM components' expression [35]. Taking the above into account, we assayed the effect of breast cancer cells on the expression of HUVEC expressed ECM macromolecules.
One endothelial glycocalyx component of vital importance is hyaluronan as it plays a crucial role in the maintenance and enhancement of vascular integrity through endothelial glycocalyx modulation, caveolin-enriched microdomain regulation and interaction with endothelial HA binding proteins [42-45]. Hyaluronan represent a very large, linear glycosaminoglycan composed of 2000-25,000 repeated disaccharide units composed of D-glucuronic acid and $\mathrm{N}$-acetyl-Dglucosamine. Cancer cells themselves as well as the stromal cells are potent by the action of hyaluronidases and reactive oxygen species to digest high molecular HA into oligosaccharide-fragments of hyaluronan [46-48]. However, its effects on angiogenesis and endothelial cell function depend on its molecular size as well as its concentration [46]. High molecular weight HA (at concentrations $>100 \mu \mathrm{g} / \mathrm{ml}$ ) is anti-angiogenic, documented to inhibit cell proliferation and disrupt confluent endothelial monolayers. In contrast, HA degradation products (4-25 disaccharides) stimulate endothelial cell proliferation, migration and tube formation, actions exerted via binding to specific HA receptors in particular, CD44 and Receptor for HA-Mediated Motility (RHAMM) [49]. In the present study, following a sandwich protein binding solid phase assay, we found that HUVEC-produced HA was significantly induced by $39 \%$ when treated with MDA-MB-231-CM as compared to the theoretical content of control HUVEC plus MDA-MB-231 cells produced as mono-cultures (Fig. 6Ai). This effect was evident also in the co-culture experimental set as the HUVEC/MDA-MB-231 co-culture expressed higher amounts of $\mathrm{HA}$ as compared to the separate monoculture of these cells (Figure 6Aii). However, such up-regulation was not reported in the case of MCF-7 breast cancer cell line of low invasive potential in both experimental systems (Fig. 6A). It is worth noticing that in previous data of our lab and others, we reported that the basal levels of HA in the highly invasive breast cancer cell line MDA-MB-231 are ca 5-times higher as compared to MCF-7 cells of the low invasive phenotype [50], suggesting that the invasive potential of the breast cancer cells is 


\section{A MDA-MB-231 invasion}

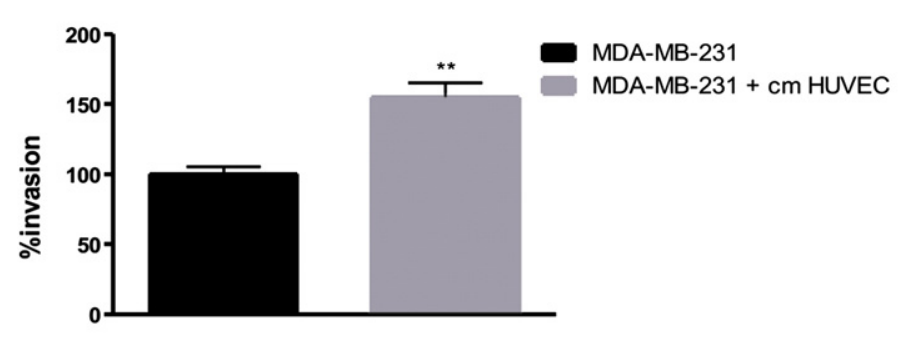

C BCCs adhesion

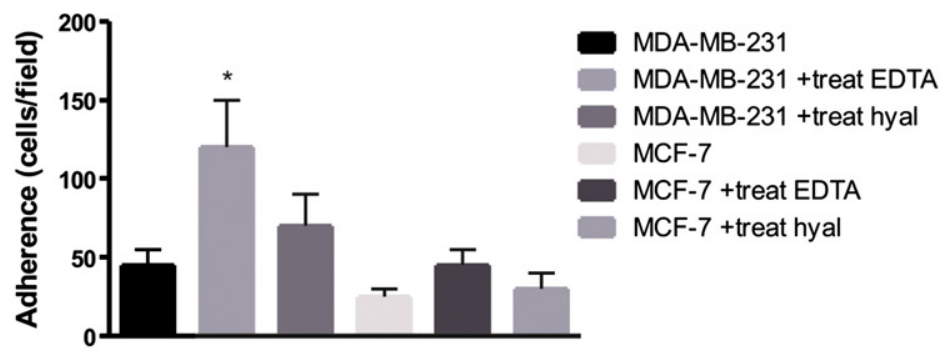

B

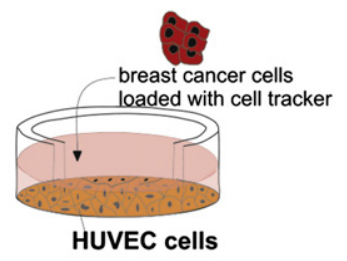

MDA-MB-231

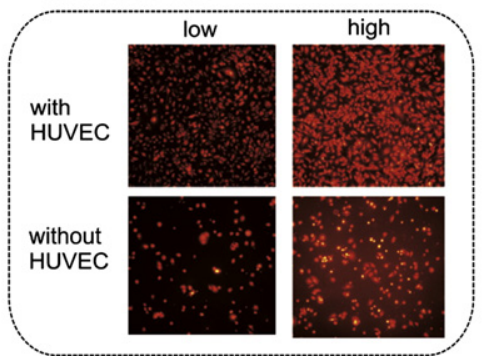

MCF-7

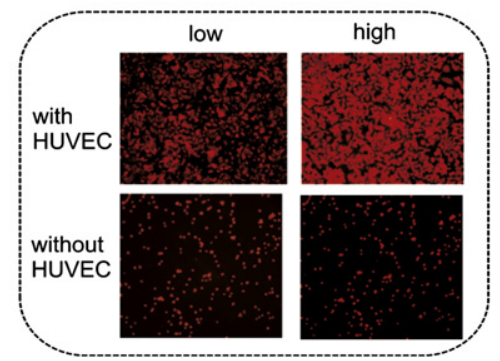

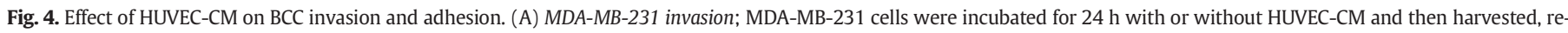

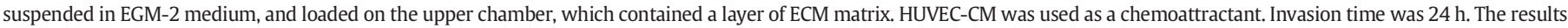

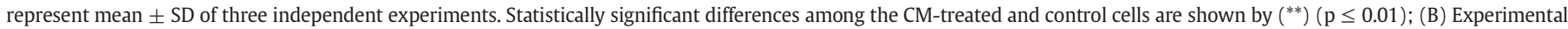

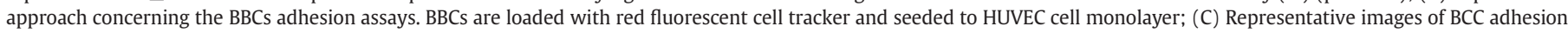

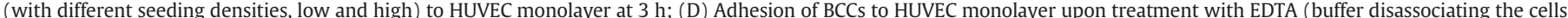

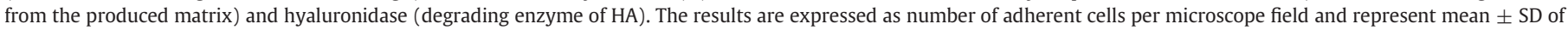
three independent experiments. Symbol marks the statistically significant levels as follows: $\left({ }^{*}\right)$ indicates $p<0.05$ as compared to untreated control cells.

correlated to the levels of HA expression. The high rate of secretion of HA by the endothelial cells induced by the cancers cells may also be in part attributed to tumor-induced inflammation [51,52].
The mRNA expression of the other critical co-player, the HA receptor CD44 standard isoform (CD44s), was ca 2.5 and 1.8-times overexpressed upon treatment with MDA-MB-231 and MCF-7 cell-derived

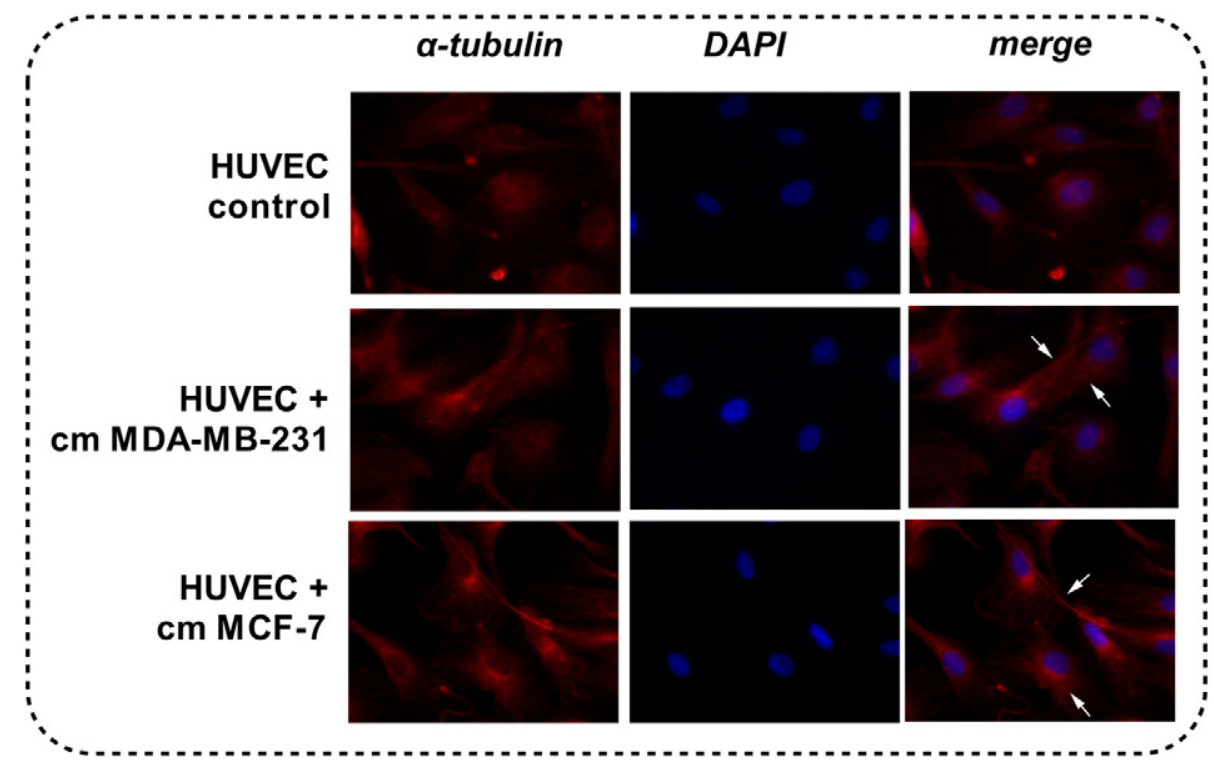

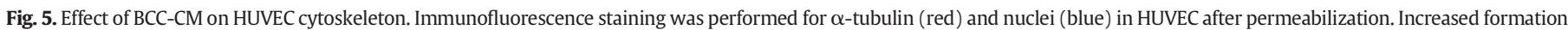
of tubulin filaments, as well as banding of tubulin filaments were observed upon treatment with BCC-CM (shown in arrowheads). 
A (i)Conditioned media

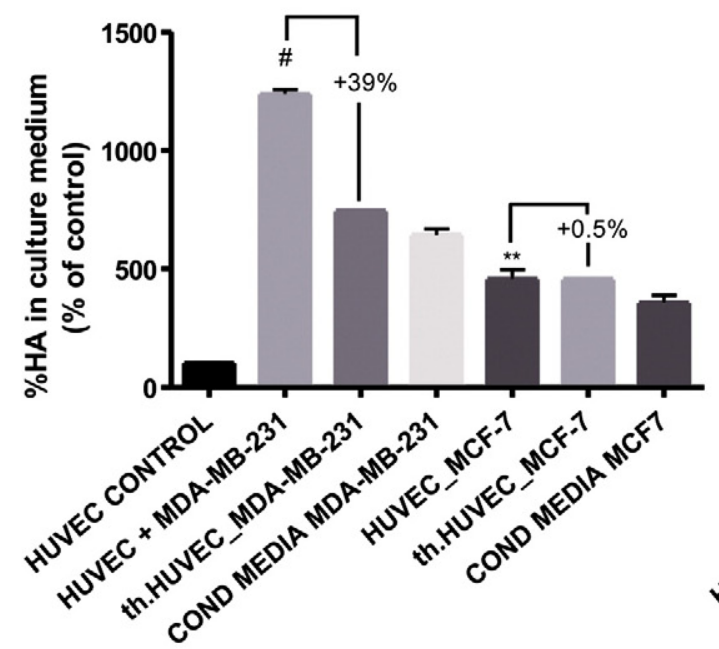

(ii)Co-culture

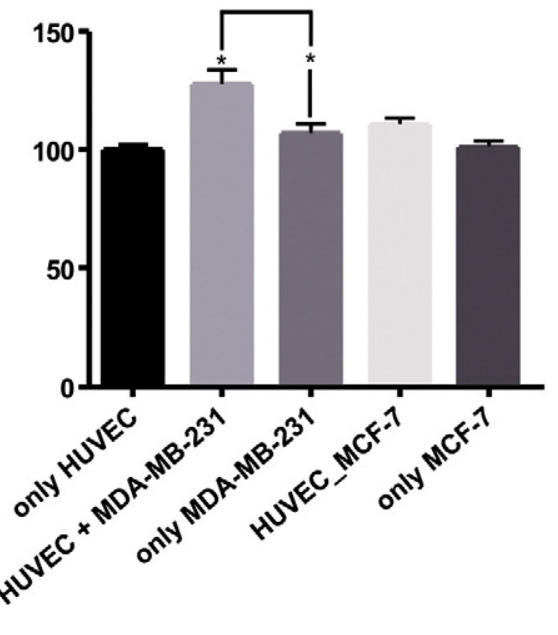

B CD44

(i) Conditioned media

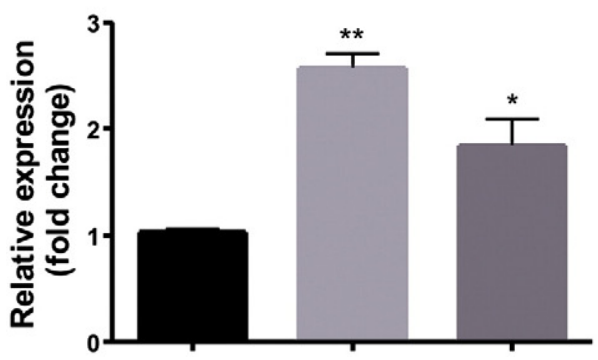

C HAS2

(i) Conditioned media

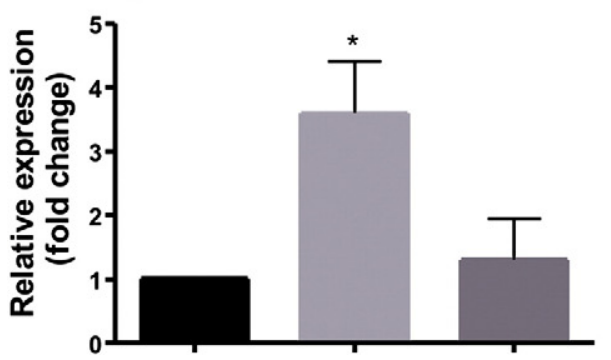

(ii) Co-culture

HUVEC control

HUVEC + MDA-MB-231

HUVEC + MCF-7

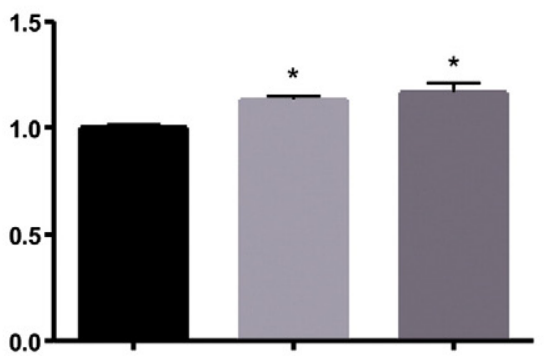

(ii) Co-culture

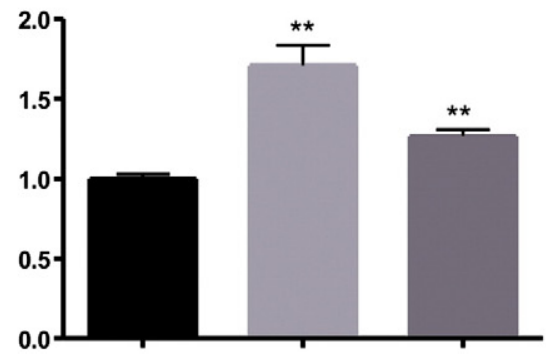

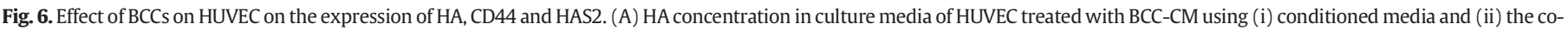

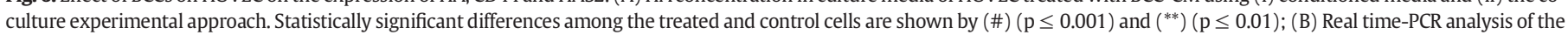

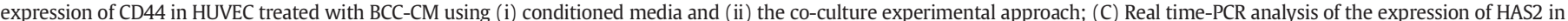

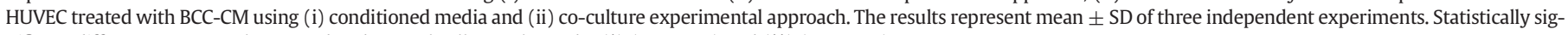
nificant differences among the treated and control cells are shown by $\left({ }^{*}\right)(p \leq 0.05)$ and $\left(^{* *}\right)(p \leq 0.01)$.

$\mathrm{CM}$, respectively as compared to the control cells (Fig. 6Bi). However, following the co-culture experimental approach, a much lower but significant overexpression (ca $20-30 \%$ increase) was noted (Fig. 6Bii). It is worth noting that the HA synthase HAS2 in HUVEC was substantially up-regulated by cancer cells in both culture models used (Fig. 6C). The effects induced from the highly metastatic MDA-MB-231 cells are in all cases higher as compared to the low metastatic MCF-7 cells. Due to its biological nature HA contributes to the formation of HA-dependent pericellular matrix, contributing to cell adhesion/de-adhesion and cell morphological changes [53]. In this study, no apparent changes in HAdependent pericellular matrix were observed, visualized by particle exclusion assay (data not shown). To strengthen this observation, it is documented in the literature that overexpression of HAS2 in vascular smooth muscle cells resulted in low pericellular HA, leading though to diminished growth and migratory phenotype as well as increased monocyte adhesion [51].

As described above (Fig. 4B), when the HUVEC cell monolayer was pretreated with hyaluronidase the increased adhesion of cancer cells 
was abolished, indicating that cancer cell adhesion is partly attributed to HA (Fig. 4B). Endothelial HA expression creates an inflammatory environment and vice versa resulting in CD44/HA primary adhesion [54]. It is worth mentioning the important role of CD44-crosslinking in integrin-mediated adhesion and transendothelial migration of breast cancer cells $[41,55]$.

Cell adhesive properties that cells exhibit to each other, their extracellular matrices and other surfaces are mediated by a variety of membrane proteins collectively known as cell adhesion molecules (CAMs). The progression of tumor malignancies is often associated with alterations in CAM profile, introducing CAMs' important role in cancer metastasis. The intercellular cell adhesion molecule-1 (ICAM-1) and vascular endothelial cell adhesion molecule-1 (VCAM-1) have been implicated in the process of cancer induced-inflammation/oxidate stress [56]. In the present study, we reported substantially up-regulated gene expression levels of these adhesion molecules in HUVEC by breast cancer cells in both culture models used. Specifically, VCAM and ICAM expression in HUVEC revealed an approximately 60 -fold and 20-fold, respectively increase induced by MDA-MB-231 CM, whereas MCF-7 CM exhibited a lower extent effect (Fig. 7Ai-Bi). In the co-culture experimental approach, a lower but significantly significant up-regulation was also observed (Fig. 7Ai-Bi). Several data revealed an implication of ICAM-1 and VCAM-1 in tumor cell extravasation and VCAM-1 in cell adhesion [57]. Leukocytes have often been used to model the interactions between circulating tumor and endothelial cells [58]. In the literature, it is highlighted that HA is the principal modulator of leukocyte-endothelial cell interaction, including events like inflammatory response upregulation of HAS2, CD44, and other adhesive molecules (ICAM-1, E-selectin, VCAM-1) [59].

The proteolytic cascade is highly implicated in the orchestrated alterations of endothelial cell interactions with the cancer cells as well as with the components of the underlying basement membrane. Matrix metalloproteinases (MMPs) have the ability to degrade components of the ECM, thus influencing cell-cell and cell-matrix interactions, crucial in the transition of endothelial cell phenotype associated with angiogenesis [60,61]. However, MMPs' contribution to angiogenesis is time-related. Here, we reported a downregulation in the expression of MMP-2 and membrane-type-1-MMP (MT1-MMP) in both culture models tested by the action of BCCs (Fig. 8A-B). This reduced remodeling ability of HUVEC induced by cancer cells may be due to the morphological changes of HUVEC during BCCs' trans-endothelial migration. In the literature it is reported that there is a direct correlation of the levels of MMPs with the extent of cell-cell and cell-ECM contacts that HUVEC form. For example, down-regulation of MMP-2 and MMP-9 is documented when HUVEC undergo morphological changes [62].

$26 \mathrm{~S}$ proteasome is a macromolecular multi-subunit complex responsible for recognizing, unfolding, and ultimately destroying proteins [63]. In a recent review of our research group we highlighted the importance of targeting proteasome and indirectly affecting ECM [30]. The proteasome possesses multiple endopeptidase activities including chymotrypsin-like (CT-L), peptidyl glutamyl peptide hydrolase-like (PGPH-L) and trypsin-like (T-L), which are localized on $\beta 5, \beta 1$ and $\beta 2$ catalytic subunits, respectively [64]. We assayed the effect of BCC-CM on the expression and activity of endothelial $\beta 5$ proteasome subunit. Our results indicated a statistically significant increase of $\beta 5$ expression subunit ( $\mathrm{ca} 50 \%$ ) especially by MDA-MB-231 CM, a result that is also correlated with increased proteasome activity (Fig. 9). There are many evidences that the ubiquitin proteasome system is implicated in the development of endothelial (dys)function, which is reflected as enhanced $26 \mathrm{~S}$ proteasome activity, an accelerated degradation of endothelialprotective molecules [65]. In another line of studies they reported that inhibition of proteasome resulted in diminished expression of HAS
A VCAM (i) Conditioned media

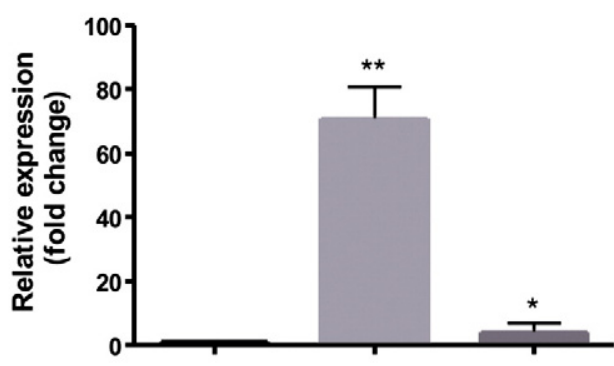

B ICAM (i) Conditioned media

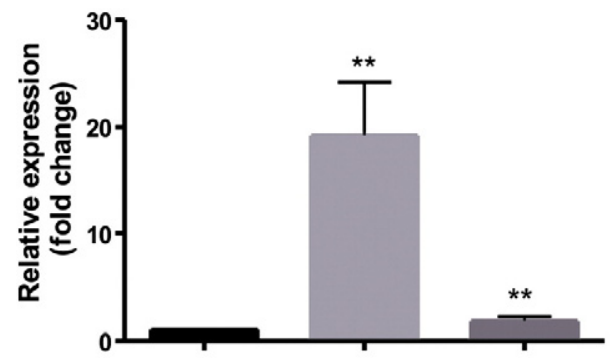

(ii) Co-culture

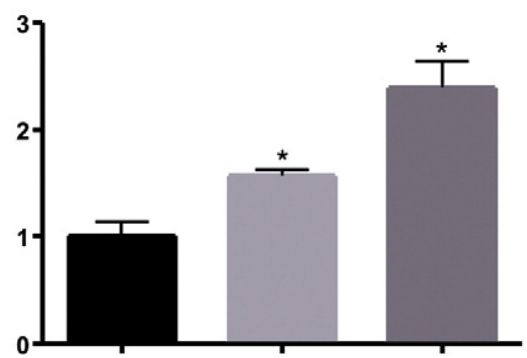

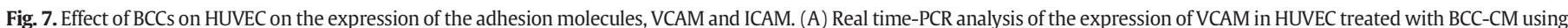

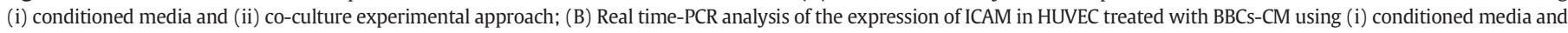

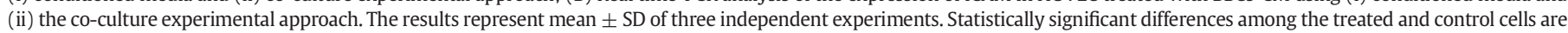
shown by $\left({ }^{*}\right)(\mathrm{p} \leq 0.05)$ and $\left({ }^{* *}\right)(\mathrm{p} \leq 0.01)$. 
A $\quad$ MMP-2

(i) Conditioned media

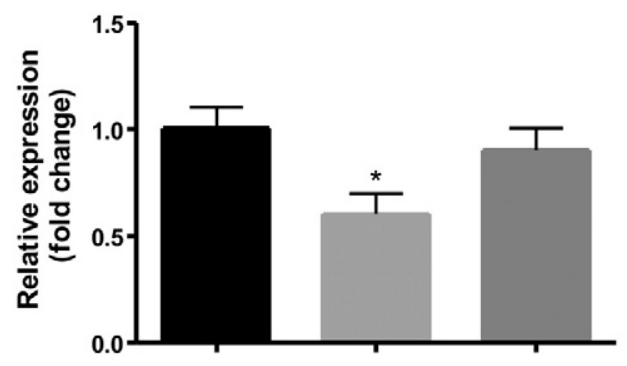

B MT1-MMP

(i) Conditioned media

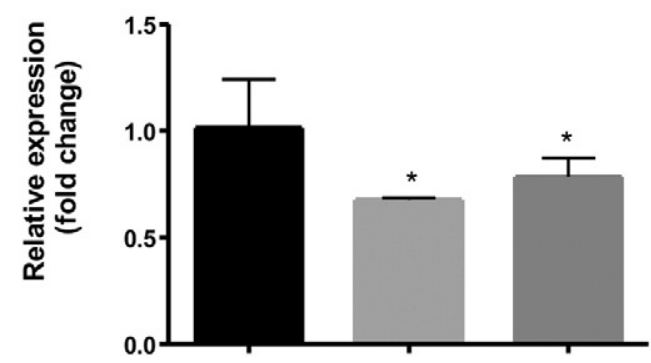

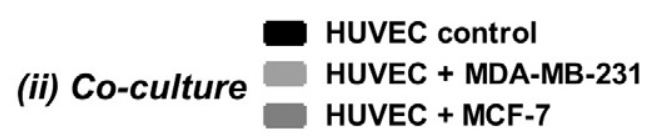

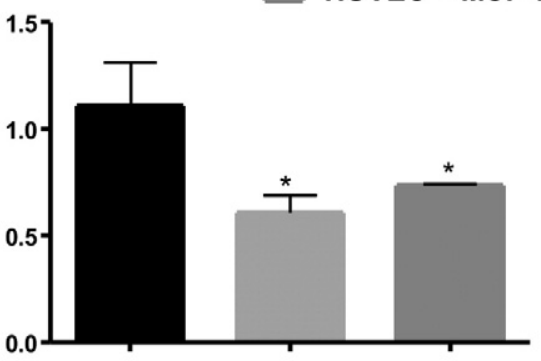

(ii) Co-culture

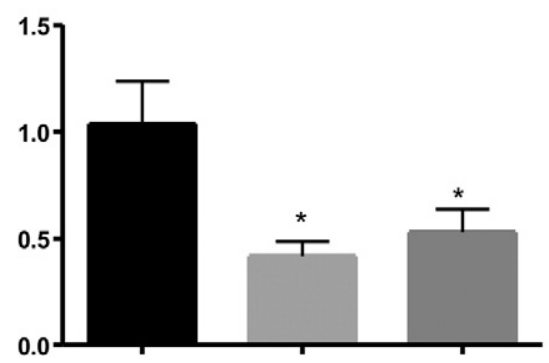

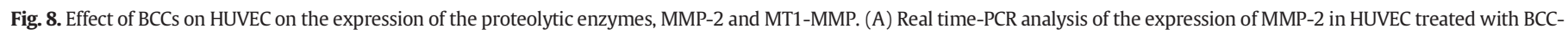

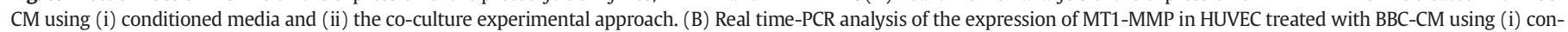

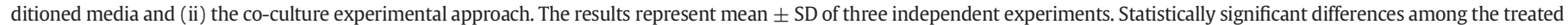
and control cells are shown by $\left({ }^{*}\right)(\mathrm{p} \leq 0.05)$ and $\left({ }^{* *}\right)(\mathrm{p} \leq 0.01)$.

and subsequent expression of HA. So in our system, we reported an upregulation of the proteasome expression levels and activity in correlation with observed altered endothelial cell properties and the increased
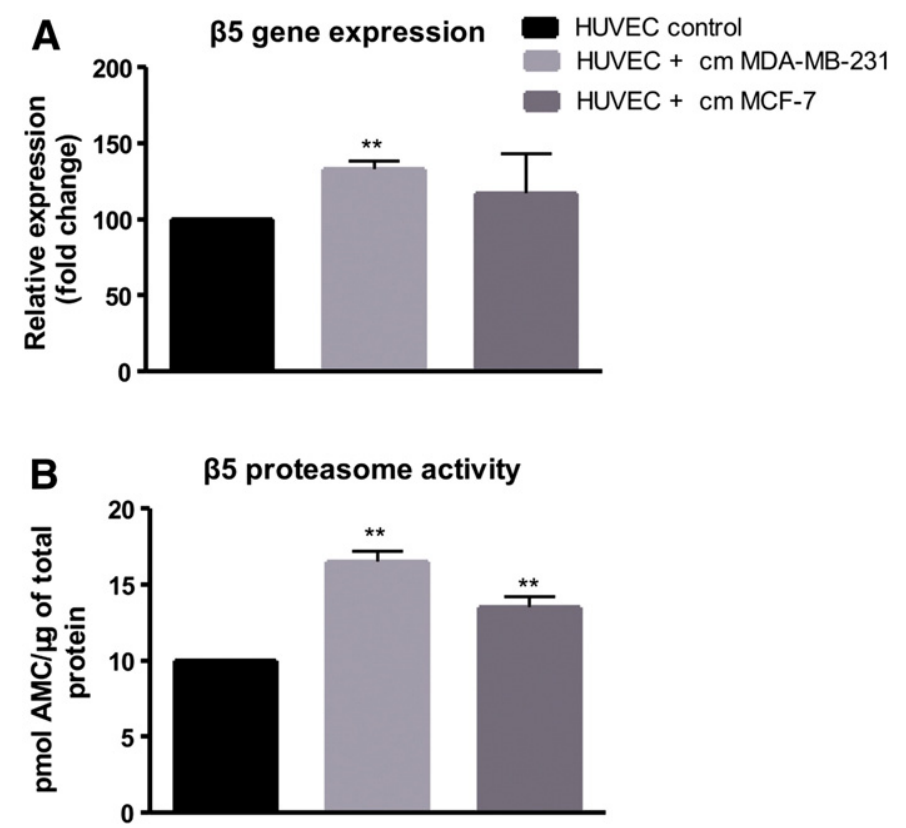

Fig. 9. Effect of BCC-CM on HUVEC-expressed proteasome. (A) Real time-PCR analysis of the expression of $\beta-5$ proteasome subunit in HUVEC treated with BCC-CM; (B) Proteasome activity of $\beta-5$ subunit of HUVEC treated with BBC-CM. The results represent mean \pm SD of three independent experiments. Statistically significant differences among the BBC-CM-treated and control cells are shown by $\left(^{*}\right)(\mathrm{p} \leq 0.05)$ and $\left(^{* *}\right)(\mathrm{p} \leq 0.01)$.
HA levels and HAS2 expression. However, it must be noted that proteasome-dependent synthesis of hyaluronan may be a cell typeand context-specific process.

\section{Conclusions}

The impact of endothelium on cancer cells and vice versa is still to a great degree undefined, and hence under investigation. How exactly the endothelium functions under these processes is still elusive. Moreover, the mechanisms by which cancer cells can transmigrate through the endothelial lining are not well understood. Therefore in this study we evaluated the effects of breast cancer cells on the expression and properties of endothelial cells. For this purpose two experimental cell culture approaches were used; one involves the use of CM media from HUVEC and BCCs and the other the co-culture of these two cell population through a transwell system. It is worth noting that the gene expression of the matrix macromolecules evaluated in this study are significantly modified either by the action of breast cancer cell conditioned media or by the co-culture models. However, the protein expression and its activity in this study haven't been evaluated, the altered gene expression profile further highlights and establishes the importance of the dynamic matrix network on cell properties. In this line, we found that such paracrine interactions affect the behavior of endothelial cells. Migration, adhesion and invasion are among the functional properties affected. It is therefore concluded that the breast cancer cell secreted effectors are of crucial importance to signal the endothelial cells and to modify their glycocalyx expression and properties. The upregulation of endothelium adhesion molecules and proteosomal activity, reorganization of the endothelial cytoskeleton, as well as Src-mediated disruption of endothelial VE-cadherin-b-catenin cell-cell adhesions summarize the driving forces of cancer cells to the endothelium in order to overpass endothelial barrier. An overview of the results obtained in this study is depicted in Fig. 10. 


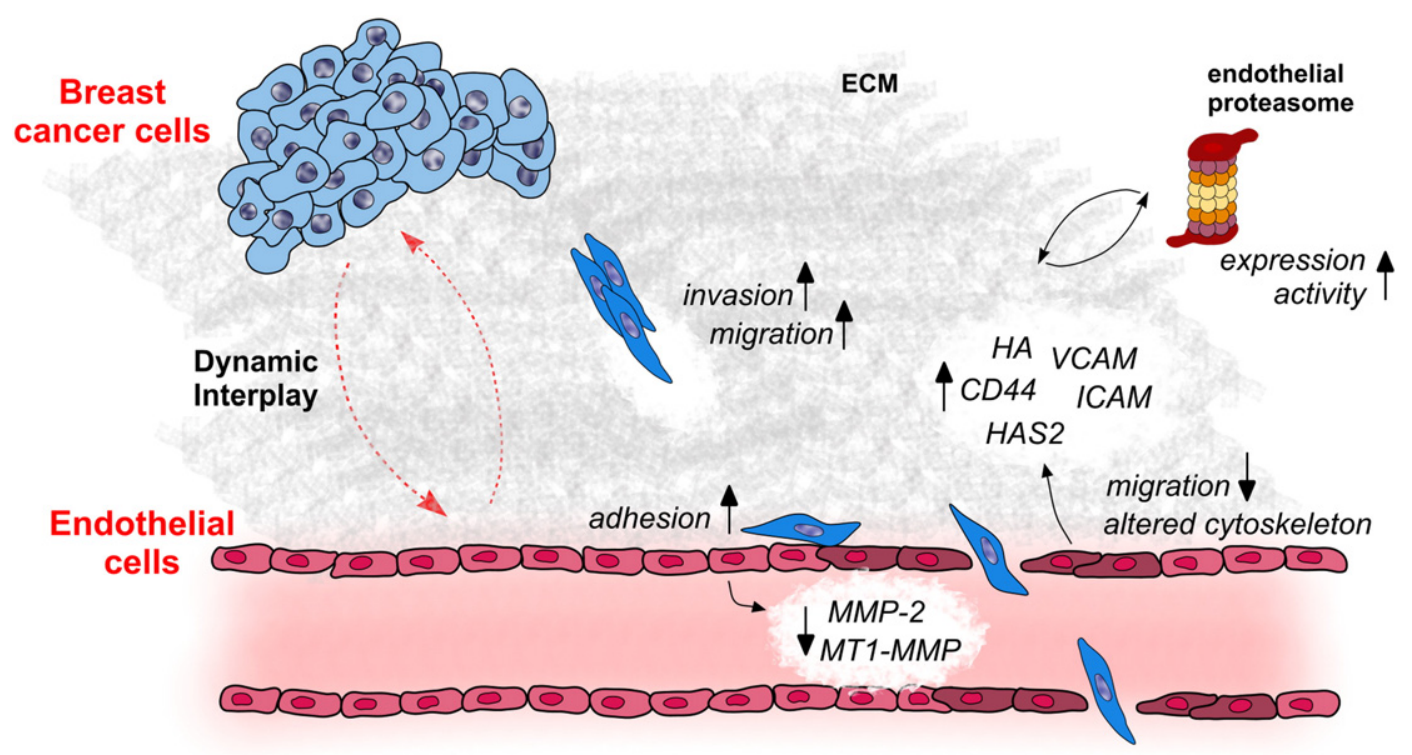

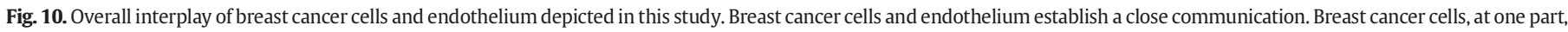

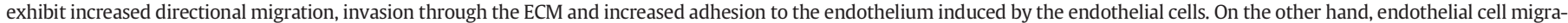

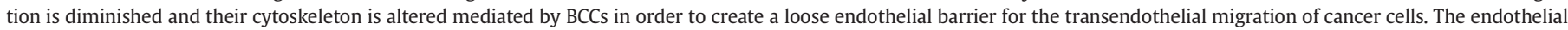

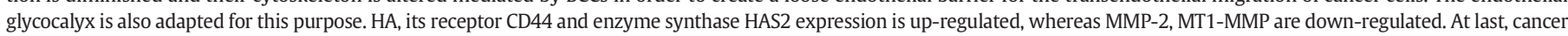
cells induce endothelial proteasome expression and activity, resulting in a dysfunctional endothelium.

These observations will force new studies in the field to evaluate in detail the underlying signaling mechanisms and open a new area to design novel drugs for pharmacological targeting of breast cancer at the ECM level.

\section{References}

[1] D. Hanahan, R.A. Weinberg, Hallmarks of cancer: the next generation, Cell 144 (2011) 646-674.

[2] D. Hanahan, R.A. Weinberg. The hallmarks of cancer, Cell 100 (2000) 57-70.

[3] K. Pietras, A. Ostman, Hallmarks of cancer: interactions with the tumor stroma, Exp. Cell Res. 316 (2010) 1324-1331.

[4] D. Hanahan, L.M. Coussens, Accessories to the crime: functions of cells recruited to the tumor microenvironment, Cancer Cell 21 (2012) 309-322.

[5] V. Gioni, T. Karampinas, G. Voutsinas, A.E. Roussidis, S. Papadopoulos, N.K. Karamanos, D. Kletsas, Imatinib mesylate inhibits proliferation and exerts an antifibrotic effect in human breast stroma fibroblasts, Mol. Cancer Res. 6 (2008) 706-714.

[6] X.N. Stahtea, A.E. Roussidis, I. Kanakis, G.N. Tzanakakis, G. Chalkiadakis, D. Mavroudis, D. Kletsas, N.K. Karamanos, Imatinib inhibits colorectal cancer cell growth and suppresses stromal-induced growth stimulation, MT1-MMP expression and pro-MMP2 activation, Int. J. Cancer 121 (2007) 2808-2814.

[7] A.R. Pries, W.M. Kuebler, Normal endothelium, Handb. Exp. Pharmacol. (2006) $1-40$.

[8] F.L. Miles, F.L. Pruitt, K.L. van Golen, C.R. Cooper, Stepping out of the flow: capillary extravasation in cancer metastasis, Clin. Exp. Metastasis 25 (2008) 305-324.

[9] F.W. Orr, H.H. Wang, R.M. Lafrenie, S. Scherbarth, D.M. Nance, Interactions between cancer cells and the endothelium in metastasis, J. Pathol. 190 (2000) 310-329.

[10] P. Lu, V.M. Weaver, Z. Werb, The extracellular matrix: a dynamic niche in cancer progression, J. Cell Biol. 196 (2012) 395-406.

[11] A.D. Theocharis, C. Gialeli, V. Hascall, N.K. Karamanos, Extracellular matrix: a functional scaffold, in: N.K. Karamanos (Ed.), Extracellular matrix: pathobiology and signaling, De Gruyter, 2012, pp. 3-20.

[12] S. Weinbaum, J.M. Tarbell, E.R. Damiano, The structure and function of the endothelial glycocalyx layer, Annu. Rev. Biomed. Eng. 9 (2007) 121-167.

[13] M. Gotte, C. Kersting, I. Radke, L. Kiesel, P. Wulfing, An expression signature of syndecan-1 (CD138), E-cadherin and c-met is associated with factors of angiogenesis and lymphangiogenesis in ductal breast carcinoma in situ, Breast Cancer Res. 9 (2007) R8.

[14] S. Reitsma, D.W. Slaaf, H. Vink, M.A. van Zandvoort, M.G. oude Egbrink, The endothelial glycocalyx: composition, functions, and visualization, Pflugers Arch. 454 (2007) $345-359$.

[15] R.V. Iozzo, L. Schaefer, Proteoglycans in health and disease: novel regulatory signaling mechanisms evoked by the small leucine-rich proteoglycans, FEBS J. 277 (2010) 3864-3875

[16] A. Oohira, T.N. Wight, P. Bornstein, Sulfated proteoglycans synthesized by vascular endothelial cells in culture, J. Biol. Chem. 258 (1983) 2014-2021.

[17] V.G. Cooke, V.S. LeBleu, D. Keskin, Z. Khan, J.T. O'Connell, Y. Teng, M.B. Duncan, L. Xie, G. Maeda, S. Vong, H. Sugimoto, R.M. Rocha, A. Damascena, R.R. Brentani, R. Kalluri,
Pericyte depletion results in hypoxia-associated epithelial-to-mesenchymal transition and metastasis mediated by met signaling pathway, Cancer Cell 21 (2012) 66-81.

[18] A. Rossi, D. Pasqui, R. Barbucci, R. Gerli, E. Weber, The topography of microstructured surfaces differently affects fibrillin deposition by blood and lymphatic endothelial cells in culture, Tissue Eng. A 15 (2009) 525-533.

[19] T. Arisaka, M. Mitsumata, M. Kawasumi, T. Tohjima, S. Hirose, Y. Yoshida, Effects of shear stress on glycosaminoglycan synthesis in vascular endothelial cells, Ann. N. Y. Acad. Sci. 748 (1995) 543-554

[20] B. Cai, J. Fan, M. Zeng, L. Zhang, B.M. Fu, Adhesion of malignant mammary tumor cells MDA-MB-231 to microvessel wall increases microvascular permeability via degradation of endothelial surface glycocalyx, J. Appl. Physiol. 113 (2012) $1141-1153$.

[21] M.M. Fuster, J.D. Esko, The sweet and sour of cancer: glycans as novel therapeutic targets, Nat. Rev. Cancer 5 (2005) 526-542.

[22] M. Nieuwdorp, M.C. Meuwese, H. Vink, J.B. Hoekstra, JJ. Kastelein, E.S. Stroes, The endothelial glycocalyx: a potential barrier between health and vascular disease, Curr. Opin. Lipidol. 16 (2005) 507-511.

[23] M. Elkin, N. Ilan, R. Ishai-Michaeli, Y. Friedmann, O. Papo, I. Pecker, I. Vlodavsky, Heparanase as mediator of angiogenesis: mode of action, FASEB J. 15 (2001) 1661-1663.

[24] L. Udabage, G.R. Brownlee, S.K. Nilsson, T.J. Brown, The over-expression of HAS2, Hyal-2 and CD44 is implicated in the invasiveness of breast cancer, Exp. Cell Res. 310 (2005) 205-217.

[25] I. Vlodavsky, N. Ilan, Y. Nadir, B. Brenner, B.Z. Katz, A. Naggi, G. Torri, B. Casu, R. Sasisekharan, Heparanase, heparin and the coagulation system in cancer progression, Thromb. Res. 120 (Suppl. 2) (2007) S112-S120.

[26] A.W. Mulivor, H.H. Lipowsky, Role of glycocalyx in leukocyte-endothelial cell adhesion, Am. J. Physiol. Heart Circ. Physiol. 283 (2002) H1282-H1291.

[27] D. Naor, S.B. Wallach-Dayan, M.A. Zahalka, R.V. Sionov, Involvement of CD44, a molecule with a thousand faces, in cancer dissemination, Semin. Cancer Biol. 18 (2008) 260-267.

[28] C.T. Mierke, Cancer cells regulate biomechanical properties of human microvascular endothelial cells, J. Biol. Chem. 286 (2011) 40025-40037.

[29] C.T. Mierke, Endothelial cell's biomechanical properties are regulated by invasive cancer cells, Mol. Biosyst. 8 (2012) 1639-1649.

[30] S.S. Skandalis, A.J. Aletras, C. Gialeli, A.D. Theocharis, N. Afratis, G.N. Tzanakakis, N.K. Karamanos, Targeting the tumor proteasome as a mechanism to control the synthesis and bioactivity of matrix macromolecules, Curr. Mol. Med. 12 (2012) 1068-1082.

[31] K.J. Livak, T.D. Schmittgen, Analysis of relative gene expression data using real-time quantitative PCR and the 2(-Delta Delta C(T)) method, Methods 25 (2001) 402-408.

[32] G.L. Van Sluis, T.M. Niers, C.T. Esmon, W. Tigchelaar, D.J. Richel, H.R. Buller, C.J. Van Noorden, C.A. Spek, Endogenous activated protein C limits cancer cell extravasation through sphingosine-1-phosphate receptor 1-mediated vascular endothelial barrier enhancement, Blood 114 (2009) 1968-1973.

[33] N. Reymond, B.B. d'Agua, A.J. Ridley, Crossing the endothelial barrier during metastasis, Nat. Rev. Cancer 13 (2013) 858-870.

[34] C.T. Mierke, D.P. Zitterbart, P. Kollmannsberger, C. Raupach, U. Schlotzer-Schrehardt, T.W. Goecke, J. Behrens, B. Fabry, Breakdown of the endothelial barrier function in tumor cell transmigration, Biophys. J. 94 (2008) 2832-2846. 
[35] J. Laferriere, F. Houle, M.M. Taher, K. Valerie, J. Huot, Transendothelial migration of colon carcinoma cells requires expression of E-selectin by endothelial cells and activation of stress-activated protein kinase-2 (SAPK2/p38) in the tumor cells, J. Biol. Chem. 276 (2001) 33762-33772.

[36] J. Reiland, L.T. Furcht, J.B. McCarthy, CXC-chemokines stimulate invasion and chemotaxis in prostate carcinoma cells through the CXCR2 receptor, Prostate 41 (1999) 78-88.

[37] A.B. Al-Mehdi, K. Tozawa, A.B. Fisher, L. Shientag, A. Lee, R.J. Muschel, Intravascular origin of metastasis from the proliferation of endothelium-attached tumor cells: a new model for metastasis, Nat. Med. 6 (2000) 100-102.

[38] C.T. Mierke, D. Rosel, B. Fabry, J. Brabek, Contractile forces in tumor cell migration, Eur. J. Cell Biol. 87 (2008) 669-676.

[39] S. Khuon, L. Liang, R.W. Dettman, P.H. Sporn, R.B. Wysolmerski, T.L. Chew, Myosin light chain kinase mediates transcellular intravasation of breast cancer cells through the underlying endothelial cells: a three-dimensional FRET study, J. Cell Sci. 123 (2010) 431-440

[40] C.T. Mierke, Physical break-down of the classical view on cancer cell invasion and metastasis, Eur. J. Cell Biol. 92 (2013) 89-104.

[41] C. Heyder, E. Gloria-Maercker, F. Entschladen, W. Hatzmann, B. Niggemann, K.S. Zanker, T. Dittmar, Realtime visualization of tumor cell/endothelial cell interactions during transmigration across the endothelial barrier, J. Cancer Res. Clin. Oncol. 128 (2002) 533-538

[42] F.E. Lennon, P.A. Singleton, Hyaluronan regulation of vascular integrity, Am. J. Cardiovasc. Dis. 1 (2011) 200-213.

[43] C.P. Wheeler-Jones, C.E. Farrar, A.A. Pitsillides, Targeting hyaluronan of the endothelial glycocalyx for therapeutic intervention, Curr. Opin. Investig. Drugs 11 (2010) 997-1006

[44] A. Genasetti, D. Vigetti, M. Viola, E. Karousou, P. Moretto, M. Rizzi, B. Bartolini, M Clerici, F. Pallotti, G. De Luca, A. Passi, Hyaluronan and human endothelial cell behavior, Connect. Tissue Res. 49 (2008) 120-123.

[45] D. Pasqui, A. Rossi, R. Barbucci, S. Lamponi, R. Gerli, E. Weber, Hyaluronan and sulphated hyaluronan micropatterns: effect of chemical and topographic cues on lymphatic endothelial cell alignment and proliferation, Lymphology 38 (2005) 50-65.

[46] N. Afratis, C. Gialeli, D. Nikitovic, T. Tsegenidis, E. Karousou, A.D. Theocharis, M.S. Pavao, G.N. Tzanakakis, N.K. Karamanos, Glycosaminoglycans: key players in cancer cell biology and treatment, FEBS J. 279 (2012) 1177-1197.

[47] M.J. Reed, M. Damodarasamy, C.K. Chan, M.N. Johnson, T.N. Wight, R.B. Vernon, Cleavage of hyaluronan is impaired in aged dermal wounds, Matrix Biol. 32 (2013) 45-51.

[48] M. Gotte, G.W. Yip, Heparanase, hyaluronan, and CD44 in cancers: a breast carcinoma perspective, Cancer Res. 66 (2006) 10233-10237.

[49] M. Slevin, J. Krupinski, J. Gaffney, S. Matou, D. West, H. Delisser, R.C. Savani, S. Kumar, Hyaluronan-mediated angiogenesis in vascular disease: uncovering RHAMM and CD44 receptor signaling pathways, Matrix Biol. 26 (2007) 58-68.
[50] P.G. Dedes, C. Gialeli, A.I. Tsonis, I. Kanakis, A.D. Theocharis, D. Kletsas, G.N. Tzanakakis, N.K. Karamanos, Expression of matrix macromolecules and functional properties of breast cancer cells are modulated by the bisphosphonate zoledronic acid, Biochim. Biophys. Acta 1820 (2012) 1926-1939.

[51] T.S. Wilkinson, S.L. Bressler, S.P. Evanko, K.R. Braun, T.N. Wight, Overexpression of hyaluronan synthases alters vascular smooth muscle cell phenotype and promotes monocyte adhesion, J. Cell. Physiol. 206 (2006) 378-385.

[52] L. Schaefer, R.V. Iozzo, Small leucine-rich proteoglycans, at the crossroad of cancer growth and inflammation, Curr. Opin. Genet. Dev. 22 (2012) 56-57.

[53] S.P. Evanko, M.I. Tammi, R.H. Tammi, T.N. Wight, Hyaluronan-dependent pericellular matrix, Adv. Drug Deliv. Rev. 59 (2007) 1351-1365.

[54] M. Mohamadzadeh, H. DeGrendele, H. Arizpe, P. Estess, M. Siegelman, Proinflammatory stimuli regulate endothelial hyaluronan expression and CD44/HA-dependent primary adhesion, J. Clin. Invest. 101 (1998) 97-108.

[55] H. Hassan, B. Greve, M.S. Pavao, L. Kiesel, S.A. Ibrahim, M. Gotte, Syndecan-1 modulates beta-integrin-dependent and interleukin-6-dependent functions in breast cancer cell adhesion, migration, and resistance to irradiation, FEBS J. 280 (2013) 2216-2227.

[56] H. Kobayashi, K.C. Boelte, P.C. Lin, Endothelial cell adhesion molecules and cancer progression, Curr. Med. Chem. 14 (2007) 377-386.

[57] O. Haddad, R. Chotard-Ghodsnia, C. Verdier, A. Duperray, Tumor cell/endothelial cell tight contact upregulates endothelial adhesion molecule expression mediated by NFkappaB: differential role of the shear stress, Exp. Cell Res. 316 (2010) 615-626.

[58] A. Takada, K. Ohmori, T. Yoneda, K. Tsuyuoka, A. Hasegawa, M. Kiso, R. Kannagi, Contribution of carbohydrate antigens sialyl Lewis A and sialyl Lewis X to adhesion of human cancer cells to vascular endothelium, Cancer Res. 53 (1993) 354-361.

[59] D. Vigetti, A. Genasetti, E. Karousou, M. Viola, P. Moretto, M. Clerici, S. Deleonibus, G. De Luca, V.C. Hascall, A. Passi, Proinflammatory cytokines induce hyaluronan synthesis and monocyte adhesion in human endothelial cells through hyaluronan synthase 2 (HAS2) and the nuclear factor-kappaB (NF-kappaB) pathway, J. Biol. Chem. 285 (2010) 24639-24645.

[60] C. Gialeli, A.D. Theocharis, N.K. Karamanos, Roles of matrix metalloproteinases in cancer progression and their pharmacological targeting, FEBS J. 278 (2011) 16-27.

[61] J.E. Rundhaug, Matrix metalloproteinases and angiogenesis, J. Cell. Mol. Med. 9 (2005) 267-285.

[62] M.S. Kiran, V.B. Sameer Kumar, R.I. Viji, P.R. Sudhakaran, Temporal relationship between MMP production and angiogenic process in HUVECs, Cell Biol. Int. 30 (2006) 704-713.

[63] A. Navon, A. Ciechanover, The $26 \mathrm{~S}$ proteasome: from basic mechanisms to drug targeting, J. Biol. Chem. 284 (2009) 33713-33718.

[64] A. Ciechanover, Intracellular protein degradation from a vague idea through the lysosome and the ubiquitin-proteasome system and on to human diseases and drug targeting: Nobel Lecture, December 8, 2004, Ann. N. Y. Acad. Sci. 1116 (2007) 1-28.

[65] K. Stangl, V. Stangl, The ubiquitin-proteasome pathway and endothelial (dys)function, Cardiovasc. Res. 85 (2010) 281-290. 